\title{
Research on Enterprise Business Model Based on Destructive Innovation
}

\author{
Yuning $\mathrm{Wu}^{1, \text { a }}$ \\ ${ }^{1}$ Yunnan University, Dianchi College, Kunmimg, Yunnan Province, China, 650031 \\ ${ }^{\mathrm{a}}$ email,
}

Keywords: Destructive Innovation, Business Model

\begin{abstract}
In this paper, we use the destructive innovation theory, combined with business model design elements to build several business models taking damage as the driving force to adjust the pace in the fierce competition in the market continue to adapt to unpredictable market variables.
\end{abstract}

\section{Overview of Destructive Innovation}

The Meaning of Destructive Innovation. Christensen (1997) for the first time through the study of the rise and fall of the industry, innovation and market integration, put forward the destructive innovation theory (Disruptive innovation). Christensen argues that destructive innovation strives for innovation in the competitive advantage of leading manufacturers by leveraging low-end markets, attracting consumers who are less discerning on the niche market, and even breaking zero consumption to win market share and through continuous improvement in performance. In his view, the destruction is in the original business model, product and service on the change and innovation, therefore, destruction is another new production function and business model.

In the process of destructive innovation, the product technology to maintain the original simple initial function, to redesign more convenient than the existing technology, the target market is not converted to the existing products have not yet demand the low-end market and new markets and other non- Mainstream markets. Later, with the continuous improvement of new product performance, new products will gradually erode the mainstream market, the industry leading enterprises to form damage.

The Dimension of Destructive Innovation. Destructive innovation can be judged from two dimensions: First, in accordance with the differences into the market will be destructive innovation is divided into new market damage, low-end market damage and mixed market damage; Second, according to the way of destruction and methods, disruptive innovation is divided into the destructive innovation of technology, the devastating innovation of business model and the destructive innovation of new products.

Destructive innovation in accordance with the different market points can be divided into new market damage, low-end market damage and mixed market damage. New market damage for the original non-consumer, innovative products to simplify the mainstream products of some additional features, so that lower manufacturing costs, the final price cheaper, while taking into account the ease of use, so that new consumer groups more acceptable, resulting in a new value network. In the early days of innovation, the target customers are non-consumer groups in the original market, but with the product performance, service experience, gradual improvement, destructive innovation established by the new product performance system may replace the original product performance service system, while the original old consumer groups from the original product, business and value of the network to enter a new value network. The devastating innovation of the new market is to gradually attract the original non-consumer access through the establishment of a new product performance system.

Low-end market destructive innovation is in the existing market and value network to a lower cost of business model, to attract the mainstream market companies do not value the low-end consumer groups gradually developed. This part of the crowd they may be potential customers of mainstream products, but because of purchasing power and non-essential reasons did not produce a 
purchase. This kind of destructive innovation in the process from low to high-end market can be relatively easy to develop a market demand for product improvement order. Low-end market damage is not to create a new market, but by reducing the cost of manufacturing cost-effective products or services strategy, in the original product performance system to seek neglected low-end customer groups or through the market segment customer segments in order to achieve gradual development.

Mixed market damage is a combination of low-end market damage and new market damage. Mixed market damage will reduce the price of products and simplify the function at the same time, the introduction of some new value effect. Therefore, the mixed market damage mainly around how the effective integration of internal and external resources, how to effectively provide and deliver quality and cheap value proposition, while attracting low-end users, the original non-consumer groups to attract over, so by expanding the original Market capacity or open up new markets to achieve financial revenue growth.

According to the ways and means of destruction, destructive innovation can be divided into the destructive innovation of technology, the devastating innovation of business model and the destructive innovation of new products. Technological innovation and business model innovation are often interrelated and mutually reinforcing. Technological innovation only with the appropriate business model, in order to better reflect its value, the market eventually to produce economic benefits, they have to rely on the creation of business models. At the same time, the creation of business models, we must continue to tap new resources and skills, in the new technology paradigm to build the competitive advantage of enterprises. Therefore, destructive technology needs a synergistic effect with the destructive business model in order to produce a market economic effect, resulting in destructive innovation of economic effects.

\section{Business Model Innovation}

The Meaning of Business Model Innovation. Business model innovation is a design process based on value proposition covering the patterns of revenue and cost related to resources and processes. Innovation must change the elements of business model. The implementation of business model innovation is no longer a closed system, but an open platform system, the enterprise is no longer a simple link in the industry chain, but a social network in a core node, uphold the "cooperation, a total of win "concept, the enterprise boundaries to expand to the interests of enterprises and trade structure of the impact of all stakeholders, and ultimately set up to the enterprise itself as the core of the commercial ecosystem.

Business Model Design. The business model design includes nine elements from three aspects: business conditions, products, or services:

$\square$ Value proposition: the value that an enterprise can provide to its consumers through its services and products.

$\square$ Market segments: that is, the target consumer groups aimed at the enterprise, that is, the value of the object.

$\square$ Customer relationship: that is, between enterprises and consumers established by the link.

$\square$ Core resources and capabilities: the ability and qualifications that companies need to implement their business model.

$\square$ Value configuration: the configuration of resources and activities.

$\square$ Cost structure: the use of the tools and methods used to describe.

$\square$ Distribution channels: the way businesses use to reach consumers.

$\square$ Partner network: a network of relationships between enterprises and other companies that effectively provide value and commercialize it.

$\square$ Income model; that is, through a variety of revenue streams to create wealth. 


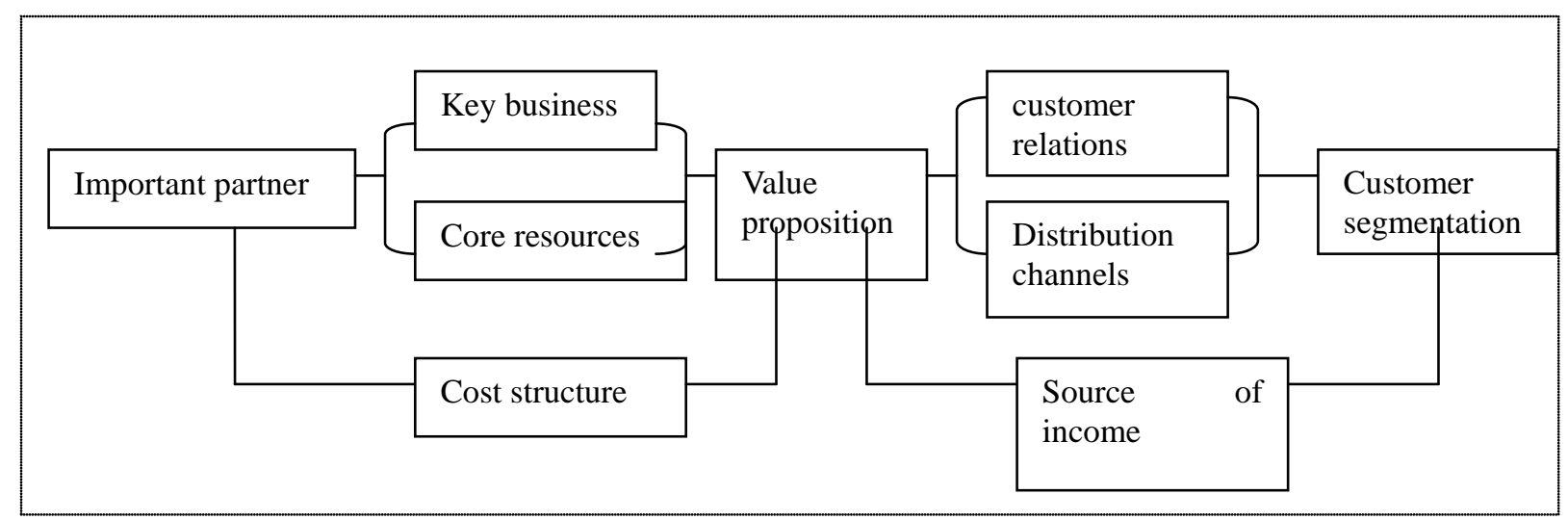

Figure 1 business model nine elements structure diagram

The design of the business model depends on the relationship between the elements, according to the following steps:

$\square$ Put forward the value proposition, and then segment customers, dredge channels, the establishment of customer relationship network

$\square$ Assessment of nuclear resources and nuclear must be competitive, master the key business, looking for partners;

$\square$ According to the cost structure clear enterprise input, adjust the price difference, determine the profit and realize the income.

\section{Business Model Selection Based on Destructive Innovation}

Target Customer Model. Disruptive and innovative technology design based on the target consumer groups, the target customer model is the target customer as the core business model. In the business model innovation path is the most core path of customer value innovation, with data analysis tools, to establish their own target customer integrated information base, and then the target customer's personalized data based on its one-on-one precision marketing and humanized service. On the basis of clear demand for full of people on the basis of value innovation, put forward new value proposition to provide consumers with more innovative than competitors, differentiated value elements, and then meet consumer preferences, expand customer value space. In this model, the enterprise will be customers as their fans to operate, such as inviting them to test their own new products, and customers to start a variety of forms of interaction to understand the target customers, the collected data reclassification, refinement, finishing, we found that each customer's data characteristics, to predict the next stage of consumer demand.

This model through real-time interaction with the majority of users, real-time analysis of data, the customer's behavior and demand changes in a timely manner reflected in the data according to customer custom content, and even allow customers to participate in enterprise product design and promotion, or by the customer to produce content.

Web Site Model. Low-end market disruption requires companies to reduce the cost structure of each value activity, improve the value creation ability and the level of income must optimize and innovate the enterprise value activity structure. Web site model is through the Internet site platform, the industry's business together into a coalition, in order to achieve cost reduction, resource sharing, common profit goals.

Enterprises on the one hand according to the needs of consumers looking for the upstream supply chain, starting from the user needs for product or service design, select the supply of raw materials, production and processing, select the downstream sales channels, after-sales service and other links, until the end user to provide mature products or services, in the production of products or services in all aspects of production and business activities in the process of forming the overall industrial chain structure. On the other hand, under the conditions of resource constraints, in order to maximize the competitive advantage, enterprises can break the boundaries of the original value activities, through the non-core or non-exclusive activities of some outsourcing to achieve the core 
activities of the simplified, focused Its main core competitiveness, rich and disposable resources. Therefore, through the "vertical and horizontal" alliance, not only to complete the enterprise value activities in the value chain in the optimization, integration, the establishment of a new cost structure, but also to achieve the value chain link value; both to maintain the independence of enterprises and alliances and jointly resist the impact from outside the industry, continue to expand the power of the Union to seek a broader space for development.

Endogenous Capacity Optimization Model. Disruptive innovation in the enterprise is a systematic process, in each stage, the need for different capabilities to adapt to, so that enterprises can successfully complete the various stages of innovation tasks. The following three capabilities are essential: technical opportunity, knowledge creation, and resource integration.

Destructive innovation ultimately has a significant impact on the industrial structure, in the process, technology foresight and choice is the starting point for enterprises to seize the opportunity. Therefore, the improvement of technical opportunities to require enterprises to carry out regular innovation and the industry's major innovations in technology, marketing, technology and other aspects of the assessment, in particular, leading customers to the evaluation of innovation and maximize access to innovative information.

The knowledge creation of the enterprise is embodied in the fact that many entities in the enterprise work together to create valuable and practical products, services, ideas, processes or process processing. The foundation of destructive innovation is a discontinuous technical trajectory, which belongs to the knowledge of cognitive knowledge, which can be directly quoted by enterprises. The effect of technology accumulation is weakened, and the strength of knowledge creation is directly related to the success of innovation. This ability is also the endogenous ability of the center, building a learning organization is to enhance the key to knowledge creation.

The ability to integrate resources is the ability of an enterprise to acquire the required assets for innovation with minimal cost. Mainly rely on internal and external factors, external factors such as government guidance funds, subsidies, industry barriers and other "profit support", internal factors in addition to the traditional sense of the financial, human, physical and other tangible assets, but also includes such as technical resources, organization members asked the network of cooperative relations, positive and progressive organizational culture, corporate image shaping and other soft power.

I believe that through the theory of destructive innovation based on the business model to explore the innovation, business model innovation research can be more in-depth, so as to business model innovation and practice to provide more theoretical guidance.

\section{References}

[1] Adner, Ron; Zemsky, Peter. Disruptive technologies and the emerging of competition[J]. RAND Journal ofEconomics, Summer2005, 36

[2] Erwin Danneels. Disruptive Technology Reconsidered: a Critique and Research Agenda [J]. JoumalofProduct Innovation Management, 2004, 21

[3] Govindarajan, vijay; Kopalle, Praveen K-Disruptiveness of innovations: measurement and an assessment of reliability and validity [J]. Strategic Management Journal, Feb. 2006, 27

[4] Shi Junguo, Yu Peili, Xiang Tao. Destructive innovation technology system and industrial evolution[J]. Science Studies, 2016, 34 